\title{
ONE YEAR PROSPECTIVE STUDY OF CASES OF PREGNANCY WITH CONGENITAL MALFORMATIONS OF FETUS
}

Jyotsna HarlalkaKamra'1, Mandeep Kaur², Preeti Jain³, Suman Rana4.

1. Assistant Professor, Department of Obstetrics and Gynaecolgy , Maharaja Agresen Medical College, Agroha, Hisar.

2. Medical officer, Department of Obstetrics and Gynaecolgy, PCMS , service number 7028.

3. Senior Resident, Department of Obstetrics and Gynaecolgy , Maharaja Agresen Medical College, Agroha, Hisar.

4. Assistant Professor, Department of Paediatrics, Maharaja Agresen Medical College, Agroha, Hisar.

\section{CORRESPONDING AUTHOR}

Dr. JyotsnaHarlalkaKamra,

H.No. 2420, sector 14,

Behind Sreeram Public School,Hisar.

Email- jyotsnakamra@gmail.com

\section{HOW TO CITE THIS ARTICLE:}

Jyotsna HarlalkaKamra, Mandeep Kaur, Preeti Jain, Suman Rana. "One year Prospective Study of Cases of Pregnancy with Congenital Malformations of Fetus". Journal of Evolution of Medical and Dental Sciences 2013; Vol2, Issue 24, June 17; Page: 4342-4349.

ABSTRACT: OBJECTIVE: To study the incidence of congenital malformation, to diagnose congenital malformations by USG in antenatal period as early as possible and to find out the cause and associated factors affecting congenital malformation.MATERIALS AND METHODS: The present study was conducted for one year in the department of obstetrics and Gynaecology, Rajindra Hospital Patiala. All cases whether detected antenatally or at the time of birth were taken. The diagnosis was made by USG in antenatal cases and at the time of delivery in those cases who have no previous USG reports or antenatal checkups. RESULTS: There were total 900 deliveries, out of which 831 were live born and 69 were still born. Congenital malformations were present in 62 cases out of which 23 were live born, 29 were still births and there were 10 cases of abortion. The overall incidence of congenital malformations in the present study was 68.89/1000 births (6.889\%).Out of total 62 cases of congenital malformations, CNS malformations were found to be the most common (66.13\%), followed by musculoskeletal system (24.19\%). In the present study USG was found to be a good method of screening of congenital malformations with high specificity (100\%) and sensitivity (73.21\%). The PPV was $100 \%$ and NPV was $98.01 \%$. The percentage of false positive results was $0 \%$ but that of false negative was $26.78 \%$. CONCLUSION: Ignorance, illiteracy and unawareness about the availability of USG, lack of adequate antenatal checkups is the main cause of late diagnosis of congenital malformations. Best effort should be put in to make the diagnosis of congenital malformations early so that referral can be made at the earliest for early intervention and planned delivery at an appropriate center.

KEYWORDS: congenital malformations, USG, antenatal, central nervous system

INTRODUCTION: One of the most traumatic experiences not only for the pregnant females, but also for the obstetrician is to deliver a congenitally malformed fetus. It is estimated that each year, more than 4 million children are born with serious birth defects that cause death or lifelong disability for 


\section{ORIGINAL ARTICLE}

the fetus or baby and hardships for the entire family. According to WHO, 1992 incidence of congenital malformations is 17-30/1000 live births and the congenital heart defects are the most common congenital malformations

Currently, the most widely used technique for fetal evaluation is2 dimensional real-time ultrasound. More recent advances involve the use of 3 dimensional ultrasound. Detection of birth defects is a major reason for which screening antenatal ultrasound is advocated (Carvalho MH et al, 2002).Ultrasound scan is currently considered to be a safe, non-invasive, accurate and cost-effective investigation of the fetus.

MATERIAL AND METHODS: The present study was conducted in the OPD and labor room of the department of obstetrics and Gynaecology, Rajindra Hospital Patiala. This was one year study (September 2006 to august 2007) and all cases whether detected antenatally or at the time of birth were taken. A detailed history was taken. Relevant information regarding maternal age, gestational age, sex, community, birth weight, birth order and consanguinity was documented. Significant antenatal history like maternal illness, ingestion of drugs, exposure to radiation and complications of labor was recorded. The diagnosis was made by USG in antenatal cases and the time of delivery in those cases who have no previous USG reports or antenatal checkups Various parameters like age, parity, booked/unbooked, rural/urban, socioeconomic status, sex of baby, type of congenital malformations, USG done/not done were taken. Following observations were made from the study:

OBSERVATIONS: As evident from table1, there were total of 900 deliveries out of which there were 831 live births and 69 were stillbirths. Total number of babies with congenital malformations were 62 out of which there were 23 live born babies, 29 still born babies and 10 were aborted ( $<20 \mathrm{wks}$ ). Incidence of congenital malformations in the present study is $68.89 / 1000$ births $(6.889 \%)$

TABLE 1: GENERAL SURVEY OF CONGENITAL MALFORMATIONS

\begin{tabular}{|l|l|}
\hline Groups & No. of Cases \\
\hline Total deliveries & 900 \\
\hline Total number of babies & 900 \\
\hline Total live born babies & 831 \\
\hline Live born babies with cong. Malf. & 23 \\
\hline Total still births & 69 \\
\hline Still births with cong. Malf. & 29 \\
\hline No. of abortions of cong. Mal. Fetuses $<20 \mathrm{wk}$ & 10 \\
\hline Total no. of male babies & 526 \\
\hline Male babies with cong. Malf. & 30 \\
\hline Total female babies & 372 \\
\hline
\end{tabular}




\section{ORIGINAL ARTICLE}

\begin{tabular}{|l|l|}
\hline Female babies with cong. Malf. & 30 \\
\hline Fetuses with concealed sex & 2 \\
\hline Total fetuses with cong. Malf. & 62 \\
\hline No. of booked cases & 404 \\
\hline No. of unbooked cases & 496 \\
\hline Incidence of babies with cong. Malf. & $68.89 / 1000(6.889 \%)$ \\
\hline
\end{tabular}

Table 2: COMPARISON OF CONGENITAL MALFORMATIONS IN LIVE/STILL BIRTHS

\begin{tabular}{|l|l|l|l|l|}
\hline Birth status & $\begin{array}{l}\text { Malformed } \\
\text { fetuses }\end{array}$ & $\begin{array}{l}\text { Normal } \\
\text { babies }\end{array}$ & Total Babies & $\begin{array}{l}\text { Incidence of Malf./ } \\
1000\end{array}$ \\
\hline Live birth & 23 & 808 & 831 & $27.06(2.76 \%)$ \\
\hline Still birth & 29 & 40 & 69 & $420.2(42.02 \%)$ \\
\hline Total & 52 & 848 & 900 & \\
\hline
\end{tabular}

TABLE 2 clearly indicates that the incidence of congenital malformations is more in still born babies as compared to live born babies and the difference is statistically significant $(p<0.05)$.

TABLE 3: DISTRIBUTION OF MALFORMATIONS IN DIFFERENT SYSTEMS

\begin{tabular}{|l|l|l|l|}
\hline System involved & $\begin{array}{l}\text { No. of cases having } \\
\text { cong. Malf. }\end{array}$ & \%age & $\begin{array}{l}\text { Incidence per } \\
1000 \text { births }\end{array}$ \\
\hline CNS & 41 & 66.13 & 45.55 \\
\hline Musculoskeletal group & 15 & 24.19 & 16.66 \\
\hline Orofacial group & 7 & 11.29 & 7.77 \\
\hline CVS & 6 & 09.67 & 6.66 \\
\hline Gastrointestinal & 5 & 08.06 & 5.55 \\
\hline Genitourinary & 4 & 06.45 & 4.44 \\
\hline Miscellaneous & 9 & 14.51 & 10 \\
\hline
\end{tabular}

Out of total 62 cases of congenital malformations, CNS malformations were found to be the most common (45.55/1000), followed by musculoskeletal system $(16.66 / 1000)$, miscellaneous (10/1000), orofacial group (7.77/1000), CVS (6.66/1000), GIT system (5.55/1000) and genitourinary system $(4.44 / 1000)$.

In the present study, incidence of congenital malformations was found to be more in unbooked cases than in those with booked cases $(7.66 \%$ vs $5.94 \%)$ and was more in rural population $(7.15 \%)$ as compared to urban population $(6.50 \%)$ the difference is statistically significant $(\mathrm{p}<0.05)$. 
The highest proportion of malformed babies, $41.94 \%$ were born to parents of lower middle class. 58.06\% malformed babies were belonged to combined poor \& lower middle class. This indicates that congenital malformations are more in lower social class groups and rural population and it is suggested that malnutrition of pregnant mother, poor hygiene and living status could have contributed to a higher incidence in these classes.

The incidence of congenital malformations was more in female babies as compared to male babies with a difference $(8.77 \%$ vs $5.70 \%)$ which is very much significant $(p<0.05)$ statistically.

The rate of fetal malformations was found to be highest in 25-29 year age group (13.04\%) followed by age group $>35$ years (6.12\%). The rate of congenital malformation was observed to be lowest in age group $<19$ year. It was observed that the incidence of congenital malformations was more in multigravida as compared to primigravida and maximum in second gravida $(10 \%)$ followed by gravida four(8.79\%). The incidence was lowest in primigravida.

TABLE 4: HIGH RISK CASES OF PREGNANCY AND CONGENITAL MALFORMATIONS

\begin{tabular}{|l|l|l|}
\hline \multirow{2}{*}{ High risk factor } & \multicolumn{2}{|c|}{ No. of cases } \\
\cline { 2 - 3 } & No. & \%age \\
\hline Oligohydramnios & 9 & 14.52 \\
\hline Polyhydramnios & 8 & 12.90 \\
\hline Age (>35 years) & 6 & 9.68 \\
\hline Prev. history of cong. Malformation & 5 & 8.06 \\
\hline Prev. H/o 2 or more abortions & 2 & $3.22 \%$ \\
\hline H/o epilepsy & 1 & $1.61 \%$ \\
\hline Jaundice & 1 & $1.61 \%$ \\
\hline Diabetes Mellitus & 1 & $1.61 \%$ \\
\hline
\end{tabular}

The table no 5 reveals an association between various obstetrical conditions and the occurrence of congenital malformations.

Table 5: CONGENITAL MALFORMATIONS AND ULTRASONOGRAPHY

\begin{tabular}{|l|l|l|l|}
\hline USG & $\begin{array}{l}\text { Control } \\
\text { Group }\end{array}$ & Study group & Total \\
\hline Done & 738 & 56 & 794 \\
\hline Non done & 100 & 6 & 106 \\
\hline Total & 838 & 62 & 900 \\
\hline
\end{tabular}

In the present study, USG was done in 794 cases, out of which 738 cases were without any congenital malformations and 56 were with malformations. USG was not done in 106 cases out of which 100 were without congenital malformations and 6 cases were with congenital malformations. 


\section{ORIGINAL ARTICLE}

\section{TABLE 6: USG IN DIAGNOSIS OF CONGENITAL MALFORMATIONS}

\begin{tabular}{|l|l|l|l|}
\hline USG Result & Cong. Anomaly & No cong. Anomaly & Total \\
\hline Cong. Anomaly & $\begin{array}{l}41 \\
\text { (True positive) }\end{array}$ & 0 (false positive) & 41 \\
\hline No cong. Anomaly & $\begin{array}{l}15 \\
\text { (False negative) }\end{array}$ & 738 (True negative) & 753 \\
\hline Total & 56 & 738 & 794 \\
\hline
\end{tabular}

The overall sensitivity of USG in diagnosing congenital malformations was $73.21 \%$ and specificity was $100 \%$. Positive predictive value of USG was $100 \%$ and negative predictive value was $98.01 \%$ whereas percentage of false negative was $26.78 \%$ and that of false positive was $0 \%$.

TABLE 7: OVERALL SENSITIVITY AND SPECIFICITY OF USG IN DIAGNOSING CONGENITAL MALFORMATIONS IN UTERO

\begin{tabular}{|l|l|l|l|l|l|l|}
\hline System & Sensitivity & Specificity & PPV & NPV & \%of false -ve & \%of false +ve \\
\hline CNS & 97.22 & 100 & 100 & 99.86 & 2.78 & 0 \\
\hline Musculoskeletal & 46.15 & 100 & 100 & 99.11 & 53.85 & 0 \\
\hline Orofacial & 33.33 & 100 & 100 & 99.49 & 66.66 & 0 \\
\hline GIT & 100 & 100 & 100 & 100 & 0 & 0 \\
\hline GUT & 100 & 100 & 100 & 100 & 0 & 0 \\
\hline CVS & 40 & 100 & 100 & 99.62 & 60 & 0 \\
\hline
\end{tabular}

In the present study the sensitivity of USG in diagnosing congenital malformations was found to be highest for GIT (100\%) and GUT (100\%) system followed by CNS (97.22\%) system, the sensitivity was lowest for orofacial system (33.33\%).The specificity was observed to be $100 \%$ for all systems. The PPV of USG in diagnosis of congenital malformations was again found to be $100 \%$ for all systems. The NPV was appreciably high for all systems (99-100\%).The percentage of false negative cases was observed highest in orofacial group followed by CVS group and musculoskeletal system. It was lowest in GIT and GUT (0\%) system. The percentage of false positive cases was 0 in all group.

DISCUSSION: As shown in table 8, the incidence of congenital malformations in various studies is low (1.6 to $3.7 \%)$ as compared to the present study which is comparatively high $(6.888 \%)$. Incidence is also high in still births in present study in comparison to other studies.

\section{TABLE 8: INCIDENCE OF CONGENITAL MALFORMATIONS}

\begin{tabular}{|l|l|l|l|}
\hline Study & Incidence (\%) & Incidence in stillbirths & Incidence in livebirths \\
\hline Aggarwal SS et al, 1991 & 1.6 & $16.4 \%$ & $1.6 \%$ \\
\hline Bhat BV et al, 1998 & 3.7 & $15.7 \%$ & $3.2 \%$ \\
\hline Patel ZM et al, 2005 & 1.6 & $15.8 \%$ & \\
\hline Present study & 6.889 & $42.02 \%$ & $2.76 \%$ \\
\hline
\end{tabular}




\section{ORIGINAL ARTICLE}

This wide variation in the incidence of malformations between different studies is due to various factors such as population sampled, geographical and racial difference, selection of casesliveborn, stillbirth or both and age of the baby when diagnosis is made. (Some authors did follow up of the cases upto various time period postnatally). It may also be due to the fact that this is a referral institute and more cases with congenital malformations were referred from periphery.

Our study is comparable to study done by Jain VK et al (1993) who observed significant difference between rural and urban population.

According to report of WHO, the Expert Committee 1970, the incidence of congenital malformations were more in lower socioeconomic class. Similar results were obtained by various studies as well as in the present study. This could be because of poor nutrition, poor hygiene, illiteracy, poor living status, no folic acid intake during $1^{\text {st }}$ trimester pregnancy and no antenatal checkups including timely USG during pregnancy.

In the present study, the total incidence of congenital malformations was more in females (8.77\%) than males (5.70\%). Grover N et al (2000) and Chaturvedi P et al (1993), reported no sex predilection whereas Bhat BV et al (1998), reported an increased incidence in males. Our study differs from these studies because maximum number of cases was of CNS malformations in which females outnumbered males.

In the present study, maximum incidence of congenital malformations was observed in age group $25-29$ yr. This is similar to observations made by Kulshrestha et al (1983). However Grover et al (2000), and Khanum S et al (2004) found higher incidence in age group $>35 \mathrm{yr}$ which is $2^{\text {nd }}$ most common group in this study.

In the present study, incidence is maximum in multipara. This is similar to studies done by Grover N et al (2000), Khanum S et al (2004), all of them found higher incidence in multipara

Overall recurrence rate of CNS malformations in present pregnancy is $8.06 \%$ and recurrence of NTD's is $4.83 \%$. This is comparable to studies done by Verma et al (1976), Hansmann M et al (1982), who found recurrence of NTD's between 3to 5\%.

Table 9: SPECIFICITY AND SENSTIVITY OF USG IN DIAGNOSING CONGENITAL MALFORMATIONS

\begin{tabular}{|l|l|l|}
\hline Study & Specificity & Sensitivity \\
\hline Lys et al, 1989 & $>99 \%$ & $18 \%$ \\
\hline Rosendhal et al, 1989 & $>99 \%$ & $63 \%$ \\
\hline Todros T et al, 2001 & $99 \%$ & $56 \%$ \\
\hline Balakumar K, 2004 & $98.6 \%$ & $72.2 \%$ \\
\hline Present study & $100 \%$ & $73.21 \%$ \\
\hline
\end{tabular}

The specificity of USG in diagnosing congenital malformations was high in all studies as shown in above table. Similarly the same result was obtained in our study. In the present study, overall sensitivity of USG in diagnosis of congenital malformations was $73.21 \%$ which is comparable to Balakumar K (2004) who found 72.2\% sensitivity. Rosendhal et al (1989), Todros T et al (2001) also have comparable results whereas lower rate was observed by Lys et al (1989). The variation in results in various studies is due to that, identification of birth defects is related to the training of the physician performing or interpreting the examination and directly related to the experience of the individual performing the evaluation. 


\section{ORIGINAL ARTICLE}

Table10: SENSITIVITY OF USG IN DIAGNOSING VARIOUS MALFORMATIONS

\begin{tabular}{|l|l|l|l|l|l|}
\hline Study & CNS & Musculo-skeletal & CVS & Git & Gut \\
\hline Vial et al, 2001 & $82 \%$ & $42 \%$ & $23 \%$ & $56 \%$ & $71 \%$ \\
\hline TodrosT et al, 2001 & $88 \%$ & $37 \%$ & $28 \%$ & $54 \%$ & $88 \%$ \\
\hline Balakumar K, 2004 & $39.21 \%$ & $11.79 \%$ & & & $18.09 \%$ \\
\hline Present study & $97.22 \%$ & $46.15 \%$ & $40 \%$ & $100 \%$ & $100 \%$ \\
\hline
\end{tabular}

Above table shows various studies and there comparison of USG sensitivity in diagnosing malformations of various system

CONCLUSION: Congenital malformations pose a threat for survival of a newborn in the early neonatal period. Prevention of congenital malformation can be achieved by,

1. Proper marriage counseling for avoiding early and consanguineous marriages.

2. Periconceptional folate consumption should be advised during the marriage counseling itself so that parents understand the need for the same when they are planning for an issue.

3. During pregnancy especially during first trimester mother should be advised to avoid drugs, irradiation, chemicals and infections which act as teratogenic insult.

4. Emphasis should be laid on for a regular antenatal checkup and need for atleast one antenatal ultrasound scan at around 18-20 weeks to rule out gross congenital malformations.

5. An attempt should be made to screen for high risk mothers first and then subject them to undergo investigations like high resolution ultrasound, amniocentesis and chorionic villus sampling wherever required.

6. In view of continued high incidence of congenital heart disease, fetal echocardiography should be done at around 16-20 weeks in high risk cases.

7. Best effort should be put in to make the diagnosis of congenital malformations early so that referral can be made at the earliest for early intervention and planned delivery at an appropriate center.

8. Whenever genetic etiology is suspected, the parents should be referred to genetic counselling after confirming the diagnosis by appropriate methods like karyotyping.

A rational and multidisciplinary approach with good communication between various specialities (obstetrician, ultasonographist, Paediatrician, Genetist and pathologist) and parents is essential.

\section{BIBILIOGRAPHY:}

1. Agarwal SS, Singh U, Singh PS, Singh SS, Das V, Sharma A et al. Prevalence \& spectrum of congenital malformations in a prospective study at a teaching hospital. Indian J Med Res 1991 Dec;94:413-9.

2. Balakumar K. Balku's Scan, Antenatal ultrasound screening for anomalies among singletons results of a prospective study. Calicut Medical Journal 2004;2(1):9.

3. Bhat BV, Babu L. Congenital malformations at birth--a prospective study from South India. Indian J Pediatr 1998 Nov-Dec; 65(6):873-81.

4. Carvalho MH et al. Detection of fetal structural abnormalities at the 11-14 week ultrasound scan. PrenatDiagn 2002;22(1):1-4. 


\section{ORIGINAL ARTICLE}

5. Chaturvedi P, Banerjee KS. An epidemiological study of congenital malformations in newborn. Indian J Pediatr 1993 Sep-Oct;60(5):645-53.

6. Grover N Congenital malformations in Shimla. Indian J Pediatr2000 Apr;67(4):249-51.

7. Hansmann M. Fetal ultrasonography, the screening of perintal life.A Viley Medical Publication; 1982.101-50.

8. Jain VK, Nalini P, Chandra Srinivasan S. Aust N Z J ObstetGynaecol 1993 Feb;33(1):33-6.

9. Khanum S, Noor K, Kawser CA. BSMMU, Dhaka. Studies on congenital abnormalities and related risk factors.Mymensingh Med J. 2004 Jul;13(2):177-80.

10. Kulshreshtha K, Nath LM, Upadyaya P. Congenital malformations in live born infants in Rural Community. Indian Pediatr 1983; 20:45 -49.

11. Lys F, De Wab et al. Evaluation of routine ultrasound examination for the prenatal diagnosis of malformation. European Journal of Obstetric and GynaecologicalReprot Biology 1989;30:101-9.

12. Patel ZM, Adhia RA. Birth defects surveillance study. Indian Journal of Pediatrics 2005;72:489-91.

13. Rosendhal H, Kivinen S. Antenatal detection of congenital malformations by routine ultrasonography. Obstetrics and Gynaecology 1989;73:947-951.

14. Todros, T, Capuzzo E. Galioti P. Prenatal diagnosis of congenital anomalies. Images Paediatr.Cardiol. 2001: 7: 3-18.

15. Verma IC, Jacob T. Clinical and genetic aspects of malformations of central nervous system. J All India Inst Med Sci 1976;1:164-168.

16. Vial Y, Tran et al. Screening for foetal malformation performance of routine ultrasonography in the population of swiss Cantors of Vaud. Swiss Med Wkly 2001;131:490-4.

17. WHO expert committee, the prevention of perinatal mortality and morbidity.Tech Rep Sev.No. 457, WHO, Geneva p. 15, 1970.

18. WHO.Global health situations and projections, estimates, division of epidemiological surveillance and Health Situation and Trend Assessment, 1992.

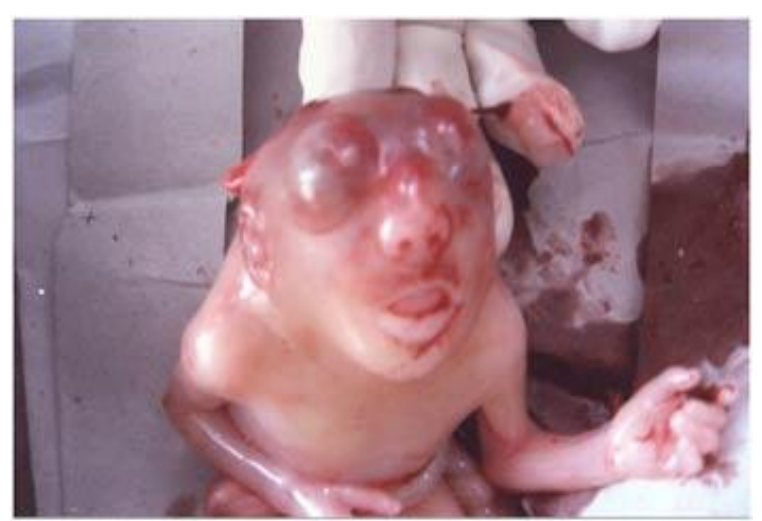

Fig. 1 Anencephaly

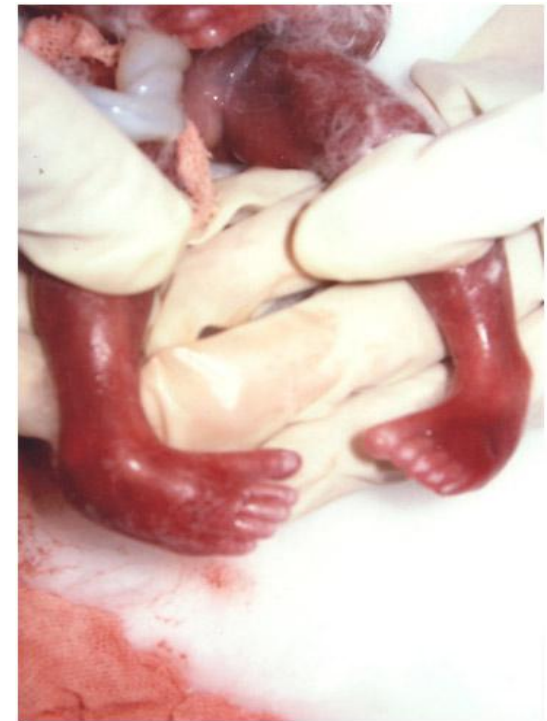

Fig. 2 Bilateral CTEV 